\title{
DYNAMICS OF TWO-PHASE FLOW ACROSS HORIZONTAL TUBE BUNDLES - A REVIEW
}

\begin{abstract}
G. Ribatski ${ }^{a}$,
and J. R. Thome

This paper presents a state-of-the-art review of the hydrodynamic aspects of two-phase flow across horizontal tube bundles. The review covers studies related to the evaluation of

École Polytechnique Fédérale de Lausanne Laboratory of Heat and Mass Transfer CH-1015 Lausanne

Switzerland agherhardt.ribatski@epfl.ch void fraction, two-phase flow behaviors and pressure drops on the shell side of staggered and in-line tube bundles for upward, downward and side-to-side flows. This study of the literature critically describes the proposed flow pattern maps and semi-empirical correlations for predicting void fraction and frictional pressure drop. These predicting methods are generally based on experimental results for adiabatic air-water flows. A limited number of experimental studies with R-11 and R-113 were also carried out in the past. The review shows noticeable discrepancies among the available prediction methods. Finally, this study suggests that further research focusing on the development of representative
\end{abstract} databanks and new prediction methods is still necessary.

Keywords: flow patterns, pressure drop, tube bundle, void fraction, two-phase flow.

\section{NOMENCLATURE}

$\mathrm{Ca}$ capillarity number, $\mu_{\mathrm{L}} \mathrm{u}_{\mathrm{G}} / \sigma$

$D$ tube diameter, $\mathrm{m}$

Fr Froud Number, G/ $\left(\rho_{\mathrm{L}}(\mathrm{gD})\right)^{1 / 2}$

$g$ acceleration due to gravity, $\mathrm{m} / \mathrm{s}^{2}$

$G$ mass velocity, $\mathrm{kg} /\left(\mathrm{m}^{2} \mathrm{~s}\right)$

$p$ pressure, $\mathrm{Pa}$

Re Reynolds number, $\mathrm{GD} / \mu$

$R i \quad$ Richardson number, $\left(\rho_{\mathrm{L}}-\rho_{\mathrm{G}}\right)^{2} \mathrm{~g}(\mathrm{~s}-\mathrm{D}) / \mathrm{G}^{2}$

$s \quad$ tube spacing, $\mathrm{m}$

$S \quad$ slip ratio, $\mathrm{u}_{\mathrm{G}} / \mathrm{u}_{\mathrm{L}}$

$T$ temperature, ${ }^{\circ} \mathrm{C}$

$u \quad$ velocity, $\mathrm{m} / \mathrm{s}$

$u_{G U} \quad$ weighed drift velocity, $\mathrm{m} / \mathrm{s}$

$U$ superficial velocity, $\mathrm{m} / \mathrm{s}$

$U_{G}{ }_{G}$ dimensionless gas velocity given by Eq. (3)

$X_{t t} \quad$ Martinelli parameter given by Eq. (7), dimensionless

\section{Greek symbols}

$\chi \quad$ vapor quality, dimensionless

$\Delta p$ pressure drop, $\mathrm{Pa}$

$\varepsilon \quad$ cross sectional void fraction, dimensionless

$\phi^{2} \quad$ two-phase frictional multiplier, dimensionless

$\mu \quad$ viscosity, Pa.s

$\rho$ density, $\mathrm{kg} / \mathrm{m}^{3}$

$\sigma \quad$ surface tension, $\mathrm{N} / \mathrm{m}$

\section{Subscripts}

two-phase gas

G0 total flow assumed to be gas

$H$ homogeneous model

$L \quad$ liquid

LO total flow assumed to be liquid

\section{INTRODUCTION}

Shell-and-tube heat exchangers are among the most used type of heat exchangers. Their applications include kettle and thermosyphon reboilers, steam generators and evaporators used in the petrochemical, process, power generation and refrigeration industries. The two-phase flow in these devices is determined by a balance between the driving hydrostatic pressure and the accelerational and frictional pressure drops. In addition, the heat transfer performance is a result of a complex interaction between the hydrodynamics and heat transfer process. Thus, in order to optimize the thermal-hydraulic design of such equipment, special attention should be paid to a reliable knowledge of the three components making up the total pressure drop - static, frictional and accelerational pressure gradients.

A reliable void fraction model is essential to calculate the static and accelerational pressure drops since it is related to important flow parameters such as average fluid density, average fluid viscosity, and average fluid velocity. In addition, the magnitude of the pressure drop is 


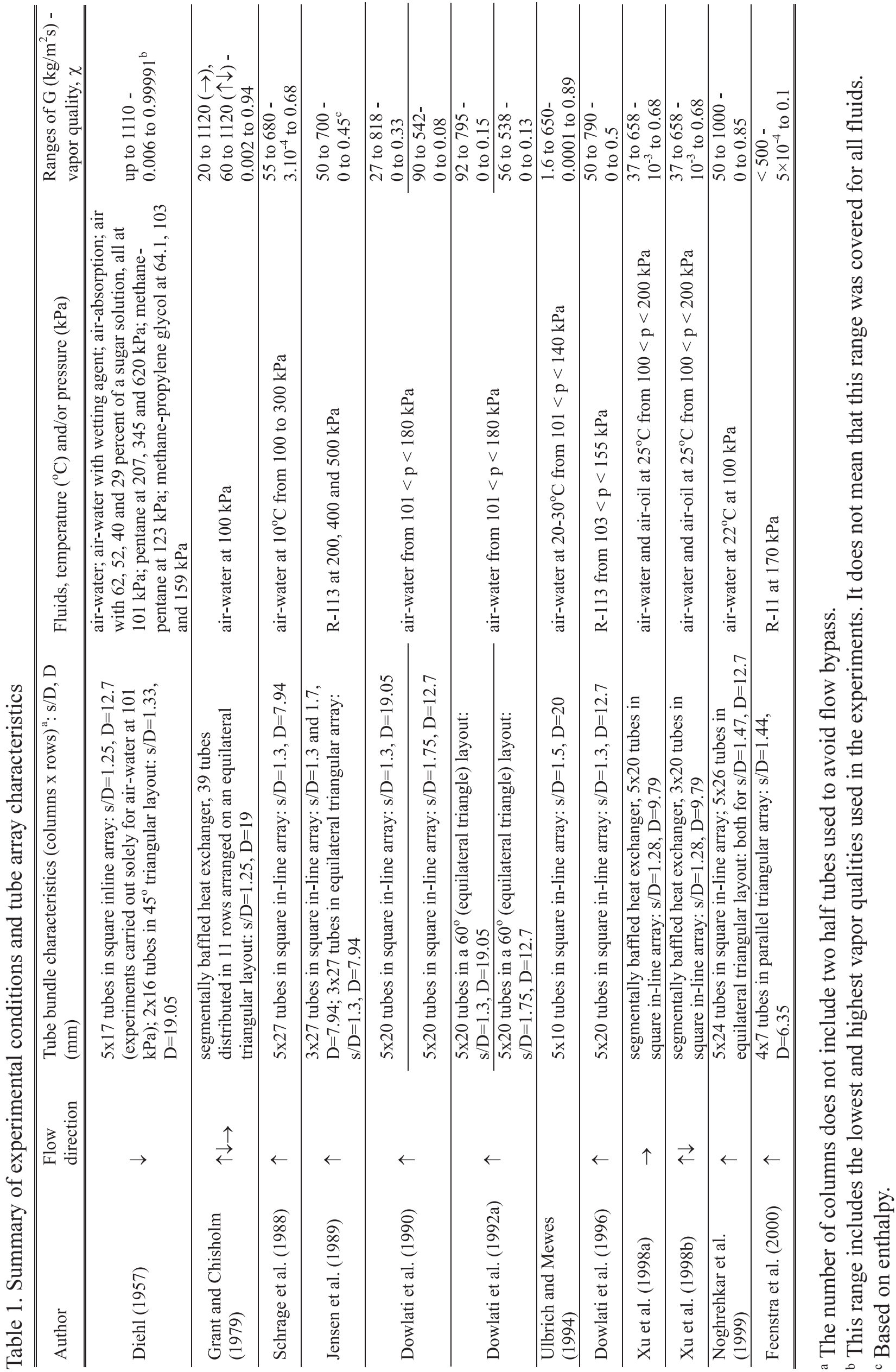


closely related to the physical structure of the twophase flow, which could present distinct characteristics according to some flow parameters. Moreover, in shell-and-tube heat exchangers operating at high fluid velocities, the two-phase flow pattern is an important aspect with respect to avoiding flow-induced vibration phenomena, which could cause tube failures, according to Feenstra et al. (2002). However, the number of investigations concerning those variables in twophase flow on the shell side of tube bundles is still limited, in comparison with gas-liquid two-phase flow in tubes.

Table 1 summarizes the experimental conditions and tube array characteristics of some published investigations concerning two-phase flow across tube bundles. These research works have focused on obtaining flow pattern maps, and semi-empirical correlations to predict void fraction and frictional pressure drops.

As shown in Tab. 1, previous works concerning this topic have been conducted on inline and staggered tube arrangements, for upward, downward and side-to-side flows. Tube diameters and tube spacing have been similar to those used in heat exchangers. No research has been carried out for enhanced surfaces. Most of the studies were conducted with air-water mixtures. There are few data available for halocarbon refrigerants, and when available they were obtained for CFC refrigerants, which are now banned in most countries. In addition, the experimental mass velocities covered by these studies, although large, are not usual of refrigeration systems, in which typical design mass velocities are in the range from 5 to $60 \mathrm{~kg} / \mathrm{m}^{2}$.

This paper provides a literature review of the dynamic aspects of two-phase flow across horizontal tube bundles. The review is focused on published studies concerning flow patterns, void fraction and frictional pressure drop.

\section{FLOW PATTERNS}

Some attempts to characterize flow patterns in two-phase flow across a tube bundle, generally by visual observations, have been carried out. Figure 1 shows schematically the suggested flow patterns. Flow pattern maps have been also proposed. In general, they are simply plots of superficial gas and liquid velocities, in which the superficial velocities are referred to the minimum cross-sectional area for flow through the tube bank. For vertical up-and-down flow and horizontal sideto-side flow, Grant and Chisholm (1979) identified by visual observations the following flow patterns: spray flow (annular), bubbly flow, intermittent flow, stratified-spray flow and stratified flow. Spray and bubbly flow were observed for either vertical or horizontal flow. The intermittent pattern was observed solely with vertical flow, and stratifiedspray and stratified patterns solely for horizontal flow. Based on these flow patterns, flow pattern maps consisting basically of a plot of $U_{G}\left(r_{G} / r_{L}\right)^{1 / 2}$ against $U_{L}\left(r_{\mathrm{L} /} m_{\mathrm{L}}\right)^{1 / 3} / s$ were proposed for both vertical and horizontal flows.

For vertical upward flow, in order to identify two-phase flow regimes in an objective manner, Ulbrich and Mewes (1994) supplemented the usual visual observations using photographic techniques and a video camera by also obtaining time traces of pressure drop. They suggested the following main flow patterns: bubbly flow, intermittent flow, and dispersed flows; the latter was subdivided into intermittent and annulardispersed flows (annular). The intermittent dispersed flow is characterized by vapor slugs within the liquid flow as irregular moving units. Although it is not characterized as a flow pattern due to being difficult to accomplish, the entire flux of liquid flowing as droplets was also observed. A flow pattern map was constructed by plotting the superficial velocities of the gas and liquid with the respective flow pattern boundaries.

$\mathrm{Xu}$ et al. (1998b) carried out visual observations of vertical up-and-down flow across a horizontal tube bundle and proposed the following flow patterns: falling film, churn flow, intermittent flow, annular flow and bubbly flow. Falling film and churn flow patterns were observed for downflow and upflow, respectively. As shown in Fig. 1, distinct configurations according to the flow direction were observed for intermittent, annular and bubbly flows. In the case of downflow, the bubbly regime, not shown in Fig. 1, is similar to the falling film pattern, except by gas bubbles dispersed in the liquid film.

Similar characteristics for spray flow (annular), bubbly flow and intermittent flow were indicated by Xu et al. (1998b) for upflow, and by Grant and Chisholm (1979) for vertical flow. Distinct flow pattern maps, based on plots of 


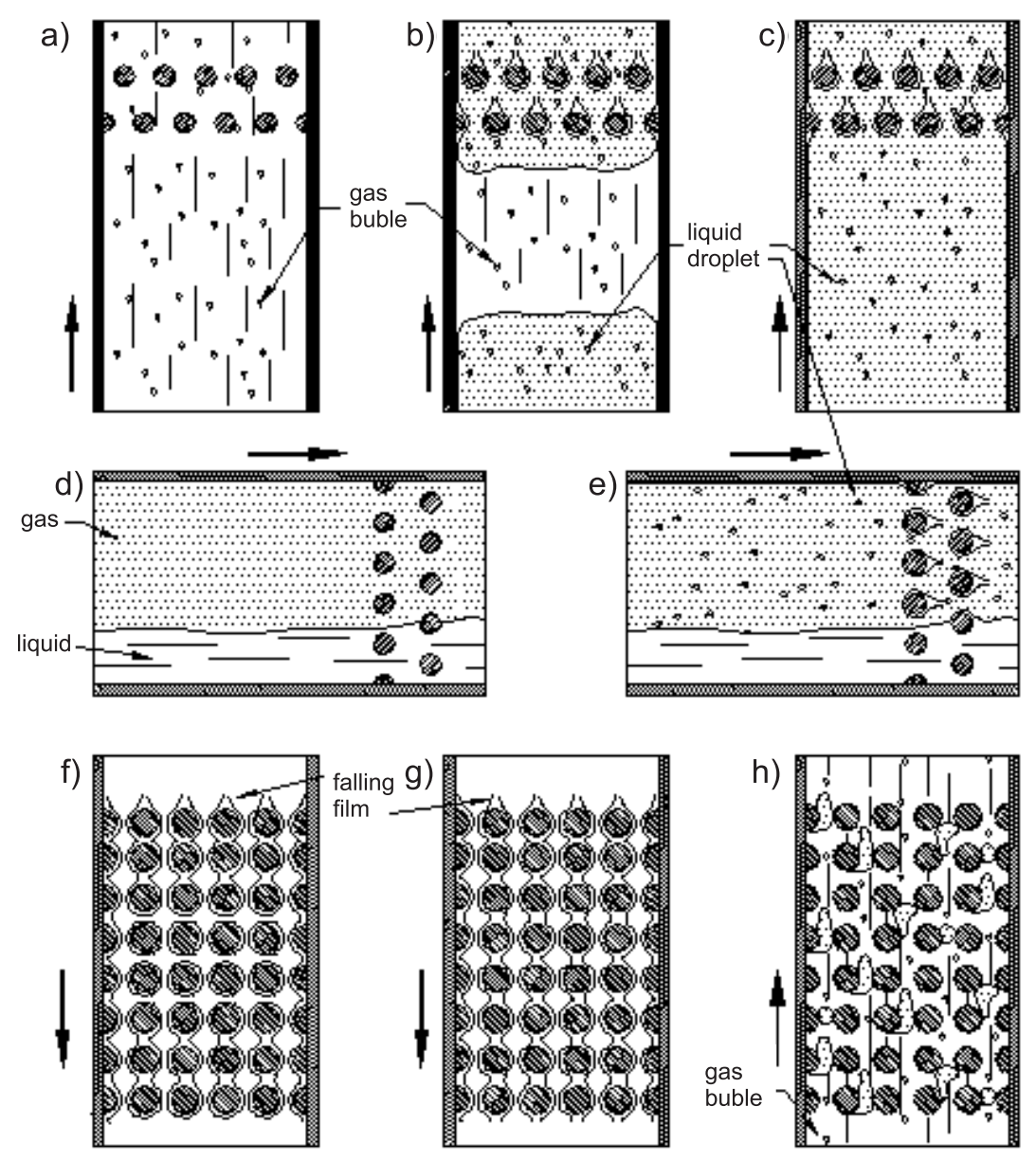

Figure 1. Proposed flow pattern categories in two-phase flow across a tube bundle; a) bubbly, b) intermittent, c) annular, d) stratified, e) stratified-spray from Grant and Chisholm (1979); f) intermittent downwards flow, g) falling film, h) churn from Xu et al. (1998b)

superficial gas velocity versus superficial liquid velocity, were proposed for vertical upflow and downflow.

Noghrehkar et al. (1999) used the probability density function (PDF) of local void fraction fluctuations to identify flow patterns in their tube bundle. The local void fraction was measured by a resistivity void probe. From the PDF data, three types of flow patterns were identified: bubbly flow, intermittent flow and annular flow. Different flow pattern maps were proposed for inline and staggered tube bundles since, according to their results, as the superficial liquid velocity increases, the transition from bubbly to intermittent flow patterns occurs at higher gas velocities for the staggered tube bundle compared to the in-line tube bundle. A more efficient break-up of larger bubbles into smaller sizes in the staggered tube bundle seems to be related to this behavior. The flow pattern maps are based on a plot of superficial gas velocity against superficial liquid velocity. Noghrehkar et al. (1999) also suggested that the technique of visual observations may not always reveal the flow pattern inside the bundle due to the fact that, using the PDF method, they have observed different flow patterns near the shell wall and inside the bundles.

Figure 2 presents a comparison of the aforementioned maps for air-water flowing upward across an in-line tube bundle. It is noted that maps constructed based solely on visual observations, shown in Fig. 2a, do not agree in a reasonable way. The discrepancy between these maps is puzzling due to the fact that the experimental conditions on which they are based were similar, and the only obvious difference is the tube diameter. On the other hand, Fig. $2 b$ shows that the proposed maps based on objective methods agree fairly well despite the fact that the authors have used distinct methods to characterize the flow patterns. Finally, a comparison between Figs. $2 \mathrm{a}$ and $2 \mathrm{~b}$ reveals reasonable discrepancies between the maps based solely on visual observations and the ones based on objective methods, principally for the bubbly regime. 
Therefore, it seems that a combination of visual observations and an objective method is the most reliable procedure to identify flow patterns experimentally. Moreover, it is clear that the flow pattern identification by means of visual observations is subjective and distinct flow regimes can be observed at different locations in the tube bundle as pointed out by Noghrehkar et al. (1999).

\section{VOID FRACTION}

From the definitions of the cross-section void fraction and velocity ratio given by ratio of gas velocity to liquid velocity, a relationship between void fraction and vapor flow quality can be obtained by a linear combination of the continuity equation for each phase. It is given by:

$$
\varepsilon=\frac{1}{1+S \cdot \frac{\rho_{G}}{\rho_{L}} \cdot\left(\frac{1-\chi}{\chi}\right)}
$$

By assuming that both phases travel at the same velocities, $S=1$ in this equation, the homogeneous void fraction is obtained. Several authors such as Schrage et al. (1988), Dowlati et al. (1990; 1992a), and Feenstra et al. (2000) have measured void fraction values significantly lower than those predicted by the homogeneous model. Discrepancies between the homogeneous model and the experimental results can be attributed to the model assumption of no slip between the phases. The validity of this assumption depends on the degree of mixture between the phases. At high mass velocity and low vapor quality, the void fraction values tend to approach the values predicted by the homogeneous model. On the other hand, at low mass velocity and especially at low vapor quality, condition in which the buoyancy effects are significant, the velocity difference between the phases is substantial.

Schrage et al. (1988) performed experiments with air-water in which the void fraction was measured using the quick-closing valves method. Although frequently used, this method does not give the superficial void fraction but the volumetric one. They are related by the slip ratio, and could present a similar value solely in the case of no slip between the phases. Their experimental data were used to create the following correlation:

$$
\varepsilon / \varepsilon_{H}=1+0.123 \cdot F r^{-0.191} \cdot \ln (\chi)
$$

This void fraction correlation consists of two parts. If the ratio $\varepsilon / \varepsilon_{\mathrm{H}}$ predicted by Eq. (2) is less than 0.1 , then $\varepsilon / \varepsilon_{H}=1$; otherwise, $\varepsilon / \varepsilon_{H}$ is equal to the value given by Eq. (2). Although 0.1 is an arbitrary value, the adopted procedure seems to agree with the aforementioned hypothesis according to which the experimental void fraction approaches to the homogeneous model value at high mass velocity and low vapor quality. In this correlation, the Froud number is the ratio between inertial and gravitational effects.
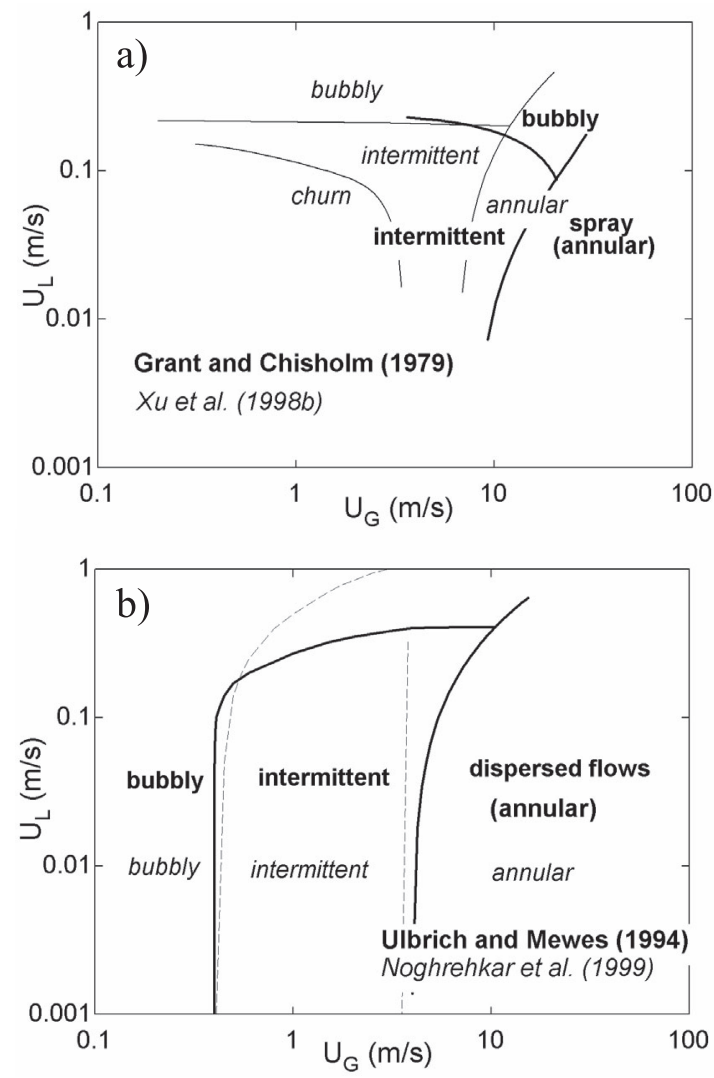

Figure 2. Comparison of shell side flow pattern maps: a) maps based on visual observations, and

b) maps based on objective methods

Dowlati and co-workers developed an extensive experimental database on void fraction in tube bundles. They measured void fraction for the experimental conditions shown in Tab. 1 using a gamma densitimeter. For a staggered tube bundle, Dowlati et al. (1992a) noted an increase in void fraction with $\mathrm{s} / \mathrm{D}$. This behavior was not observed for the in-line tube bundle in their previous study (Dowlatti et al., 1990), according to which the void fraction was apparently not affected by the tube pitch. By comparing both studies, Dowlati et al. 
(1992a) found for the staggered tube bundle a void fraction about 10 to $15 \%$ greater than that observed for the in-line tube bundle.

For given values of mass velocity and quality, Dowlati et al. (1996) obtained for R-113 lower void fractions than the values found for airwater by Dowlati et al. (1990). Analysis of Eq. (1) suggests that this behavior is related to a density ratio for R-113 four times that of air-water at atmospheric pressure. Dowlati et al. (1990) assumed that the mass velocity effects on $\varepsilon$ can be correlated by a balance of buoyancy and inertial forces. Contrary to the correlation of Schrage (Schrage et al., 1988), in which these effects were characterized by the Froud number, Dowlati and co-workers used the dimensionless gas velocity, given by Eq. (3) to fit their experimental data. These authors also found that the void fraction was quite well correlated by the dimensionless parameter using Eq. (4)

$$
\begin{aligned}
& U_{G}^{\prime}=\frac{\rho_{G}^{1 / 2} \cdot U_{G}}{\sqrt{g \cdot D \cdot\left(\rho_{L}-\rho_{G}\right)}} \\
& \varepsilon=1-\frac{1}{\left(1+c_{1} \cdot U_{G}^{\prime}+c_{2} \cdot U_{G}^{2}\right)}
\end{aligned}
$$

Despite the fact that distinct trends have been observed, Dowlati et al. (1990) suggested the values of $c_{1}=35$ and $c_{2}=1$, independent of the tube bundle characteristics, for air-water as working fluid. For R-113, Dowlati et al. (1996) suggested using $\mathrm{c}_{1}=10$ and $\mathrm{c}_{2}=1$. Dowlati and co-workers also proposed another void fraction prediction method using the phenomenological approach developed by Zuber and Findlay (1965), referred to as the drift flux model. The expression of the drift flux model, in which the average velocity of gaseous phase is defined in terms of a weighed mean drift velocity, is given by:

$$
\bar{u}_{G}=C_{0} \cdot U+\bar{u}_{G U}
$$

where $C_{0}$ is the void distribution parameter and $U$ is the superficial velocity. Applying linear regression on the experimental results, the following values of $C_{0}$ and $u_{G U}$ were obtained: airwater, $C_{0}=1.1035$ and $u_{G U}=0.33 \mathrm{~m} / \mathrm{s}$ (Dowlati et al., 1992b); R-113, $C_{0}=1.076$ and $u_{G U}=0.85 \mathrm{~m} / \mathrm{s}$ (Dowlati et al., 1996). A higher value of $u_{G U}$ for
$\mathrm{R}-113$ than that found in air-water experiments implies that the drift velocities of bubbles in R113 are higher than those for air bubbles in water. Interestingly, it does not qualitatively agree with the drift flux velocity correlation of Rouhani and Axelson (1970), according to which at atmospheric pressure R-113 presents a lower drift velocity. Moreover, at low mass flow rates, bubble size can affect the drift velocity substantially since the rise velocity of bubbles increases with size. Although a higher density difference between the liquid and vapor phases for R-113 can promote greater $u_{G U}$ values for this refrigerant, the reported results do not agree with the bubble diameter results reported by Cornwell (1990) and Dowlatti et al. (1990), according to which the air bubbles in water at 101 $\mathrm{kPa}$ and $25^{\circ} \mathrm{C}$ are up to 5 times higher than those for R-113 at $101 \mathrm{kPa}$.

$\mathrm{Xu}$ et al. (1998a; 1998b) measured volumetric void fractions by the quick-closingvalves method. For high quality values, $\mathrm{Xu}$ et al. (1998a) obtained similar values of void fraction for downflow and upflow. However, at low vapor quality, the void fraction was greater for downflow compared to upflow. Discrepancies in flow characteristics between downflow and upflow at low quality seems to be related to these trends. At high quality and a given range of mass flow rate, annular flow was observed for both flow directions. On the other hand, at low quality and upflow, the gas phase is uniformly distributed in the form of discrete bubbles in upflow, while in downflow part of the gas is separated from the liquid phase, the latter being distributed as a continuous falling film. Their data were correlated in terms of the Martinelli parameter and liquid Froud number resulting in the following relationship:

$$
\frac{\varepsilon}{1-\varepsilon}=a_{1} \cdot F r^{a_{2}} \cdot X_{t t}^{a_{3}}
$$

where $X_{t t}$, the Martinelli parameter, is evaluated for both phases being turbulent and is given by:

$$
X_{t t}^{2}=\frac{\Delta P_{L}}{\Delta P_{G}}=\left(\frac{1-\chi}{\chi}\right)^{2-m} \cdot \frac{\rho_{G}}{\rho_{L}} \cdot\left(\frac{\mu_{i}}{\mu_{c}}\right.
$$

where $\Delta P_{L}$ and $\Delta P_{G}$ are the pressure drops for the liquid and gas flowing alone, respectively. Using 
$\mathrm{m}=0.2$, distinct values of $a_{1}, a_{2}$ and $a_{3}$ according to the flow direction were used to fit their data: $a_{1}=1.95, a_{2}=0.36, a_{3}=0.833$ for horizontal flow (Xu et al., 1998a).

$a_{1}=3.70, a_{2}=0.22, a_{3}=0.44$ for downflow (Xu et al., 1998b).

$a_{1}=1.07, a_{2}=0.138, a_{3}=0.645$ for upflow (Xu et al., 1998b).

Feenstra et al. (2000) used a gamma densitimetry to obtain void fraction measurements. They proposed an expression to correlate the velocity ratios in Eq. (1). They obtained a group of dimensionless numbers by applying the Buckingham pi theorem to the variables affecting the velocity ratio. Further simplifications and the fitting of their experimental results according to the dimensionless groups gives:

$$
S=1+25.7 \cdot(R i \cdot C a)^{0.50} \cdot(s / D)^{-1}
$$

By introducing the capillarity number, this correlation was the first to incorporate surface tension effects, which can affect the bubble size and shape, on the velocity ratio. As the Froud number introduced by the previous works, the Richardson number was introduced by Feenstra et al. (2000) to account inertial and gravitational effects. The gas phase velocity in the capillarity number is a function of the void fraction, which depends on the velocity ratio. Thus, calculating the void fraction is an iterative process in this model, including solutions of Eqs. (1) and (8) starting from an assumed value. Finally, although these authors have carried out experiments with just one tube pitch, the decrease of $S$ with the increase of $s / D$ agrees qualitatively with the experimental behavior of $\varepsilon$ found by Dowlati et al. (1992a) for staggered bundles.

Figure 3 displays plots of the reduced void fraction, given given by $\varepsilon / \varepsilon_{H}$, vs. $\chi$, for the aforementioned semi-empirical correlations. As expected, these graphs reveal that similar results are given by correlations adjusted by void fraction data measured with similar methods. This behavior becomes clearer at high flow mass. If it is assumed that at very low qualities the gas is present in the form of very small bubbles, the real void fraction will approach the homogeneous void fraction. Thus, as the vapor quality tends toward zero, the reduced void fraction tends to 1 after a minimum value is reached. The reported behavior is displayed by the correlation of Xu et al. (1998b). At high mass velocities, the turbulence in the liquid phase helps mixing the two phases and a more homogeneous mixture is obtained increasing the quality value in which the minimum void fraction is reached.

\section{PRESSURE DROP}

Diehl (1957) based on a significant experimental databank (see Tab. 1), empirically correlated the shell-side two-phase pressure drop for downflow by plotting on logarithmic coordinates $\Delta P_{2 \phi} / \Delta P_{G 0}$ against $\varepsilon_{H} /\left[\left(\rho_{G} / \rho_{L}\right) \cdot \operatorname{Re}_{G 0}^{n}\right]$. Values of $\mathrm{n}$ of 0.5 and 0.2 were used for staggered tubes and in-line tubes, respectively. For the staggered tube arrangement, two distinct curves were proposed according to the range of liquid viscosity. For in-line tubes just one curve was proposed since experimental data were carried out solely for air-water mixtures for this arrangement.
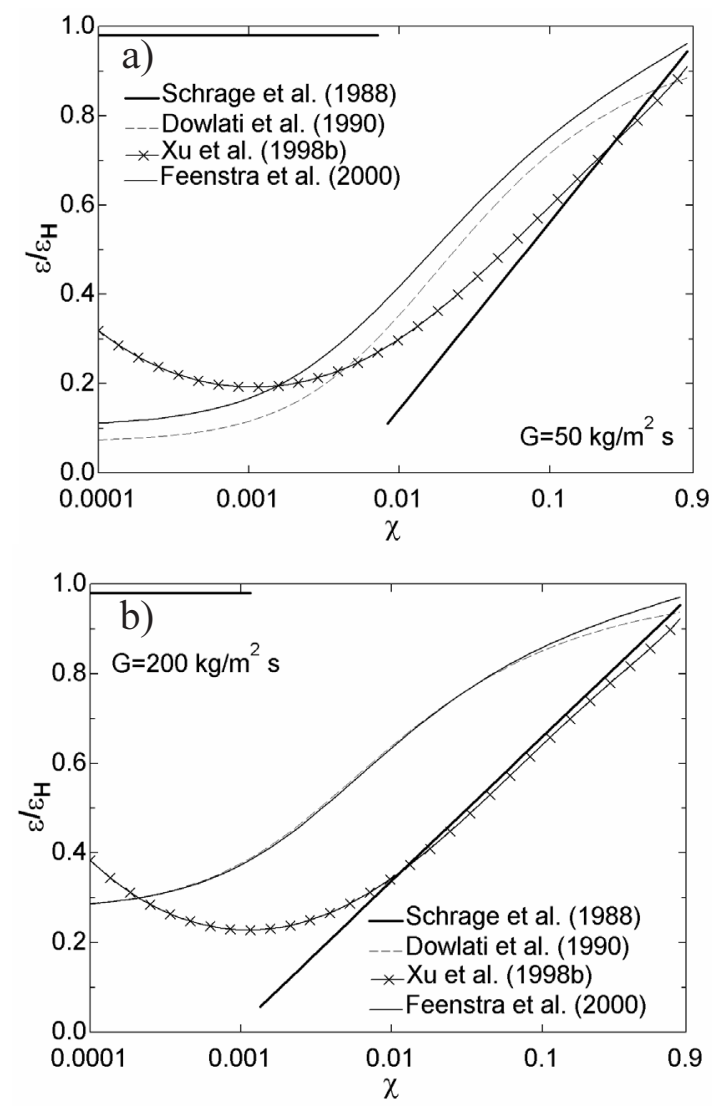

Figure 3. Variation of void fraction with gas quality according to four correlations at two mass velocities, $G=50 \mathrm{~kg} / \mathrm{m}^{2} \mathrm{~s}$ (a) and $G=200$ $\mathrm{kg} / \mathrm{m}^{2} \mathrm{~s}(\mathrm{~b})$, evaluated for air-water flowing in an in-line tube bundle, $s / D=1.75, D=19 \mathrm{~mm}$, $p=101.3 \mathrm{kPa}$ and $\mathrm{T}=25^{\circ} \mathrm{C}$ 
Due to the lack of reliable methods for predicting void fraction, Grant and Chisholm (1979) assumed that for adjacent channels in a horizontal baffled heat exchanger, the frictional component could be directly obtained from the total pressure drop due to the fact that the hydrostatic component is canceled when the upflow pressure drop is added to the downflow pressure drop. It implies a similar void fraction for downflow and upflow, which however has only been verified at high quality values according to Xu et al. (1998a). An equation proposed by Chisholm in a previous work for predicting pressure drop with two-phase flow in smooth tubes was adjusted by Grant and Chisholm (1979) using their data for shell side twophase pressure drop. Their equation is:

$$
\begin{aligned}
& \frac{\Delta P_{2 \phi}}{\Delta P_{L 0}}=1+\left(\frac{\Delta P_{G 0}}{\Delta P_{L 0}}-1\right) . \\
& \left(B \cdot \chi^{(2-m) / m} \cdot(1-\chi)^{(2-m) / 2}+\chi^{(2-m)}\right.
\end{aligned}
$$

In Eq. (9), the single-phase pressure drop ratio was evaluated using a Blausius type equation adopting experimental values for the coefficient and the exponent. According to the flow direction and flow pattern, distinct values of $\mathrm{B}$ and $\mathrm{m}$ were used to fit Eq. (9). For vertical up-and-down annular and bubbly flow, they obtained $\mathrm{B}=1.0$ and $\mathrm{m}=0.37$. For horizontal side-to-side flow, a value of 0.46 was found for the Blausius exponent and two distinct values of $B$ were obtained according to the flow pattern. $\mathrm{B}=0.75$ fits their data for annular and bubbly flows and $\mathrm{B}=0.25$ fits their data for stratified and stratified-spray flows. Data for intermittent flow were not fitted by their correlation.

After reviewing correlations for predicting frictional two-phase pressure drops across tube banks, Ishihara et al. (1980) suggested a correlation approach based on the Martinelli model to represent the two-phase friction multiplier as follows:

$$
\phi_{L}^{2}=\frac{\Delta P_{2 \phi}}{\Delta P_{L}}=1+\frac{C}{X_{t t}}+\frac{1}{X_{t t}^{2}}
$$

Databanks of previous works were fitted to obtain $\mathrm{C}=8$ and $\mathrm{m}=0.2$. For $X_{t t}<0.2$, the experimental results were predicted reasonably well but the deviations between the data and the predictions become quite large for $X_{t t}>0.2$. According to them, this trend is related to flow pattern changes not taken into account by a constant $\mathrm{C}$ value. Thus, they suggested correlating the $\mathrm{C}$ factor by the following four parameters: $X_{t t}$, $(s-D) / D,(1-\chi) / \chi$ and $U^{\prime}{ }_{G}$ used to distinguish between shear-controlled and gravity-controlled regimes. They did not identify how they obtained the frictional pressure drop from the total pressure drop. According to Burnside (1999), the C factor proposed by Ishiraha et al. (1980) together with the void fraction equation by Schrage et al. (1988) lead to quite reasonable predictions of total pressure drops for their experiments with pentane.

Schrage et al. (1988) obtained pressure drop data for the experimental conditions shown in Table 1. The experimental frictional pressure drop was obtained by subtracting from the total pressure drop the static and momentum pressure drop components. These two components were calculated using the measured void fraction. They pointed out that, in bubbly flow, $\phi_{L}^{2}$ decreases with mass velocity at a given $X_{t t}$. On the other hand, for spray and slug flow patterns, it increases with mass velocity. To fit this behavior, the $\mathrm{C}$ factor was expressed according to the following equation:

$$
C=\left(C_{1} \cdot F r^{C_{2}}\right) \cdot \ln \left(X_{t t}\right)+C_{3} \cdot F r^{C_{4}}
$$

where the coefficients $\mathrm{C}_{1}, \mathrm{C}_{2}, \mathrm{C}_{3}$ and $\mathrm{C}_{4}$, were adjusted individually for each flow pattern. To improve the data fitting, they also introduced an additional coefficient, $\mathrm{C}_{5}$, on the $1 / X_{t t}^{2}$ term of Eq. (10). These coefficients are given in Table 2.

Table 2. Coefficients in Eqs. (10) and (11) obtained by Schrage et al. (1988)

\begin{tabular}{llllll}
\hline \hline Flow pattern $^{\mathrm{a}}$ & $\mathrm{C}_{1}$ & $\mathrm{C}_{2}$ & $\mathrm{C}_{3}$ & $\mathrm{C}_{4}$ & $\mathrm{C}_{5}$ \\
\hline \hline bubbly & 0.036 & 1.51 & 7.79 & -0.057 & 0.774 \\
\hline slug $^{\mathrm{b}}$ & 2.18 & -0.643 & 11.6 & 0.233 & 1.09 \\
\hline annular $^{\mathrm{b}}$ & 0.253 & -1.50 & 12.4 & 0.207 & 0.205 \\
\hline \hline
\end{tabular}

a Flow patterns according to Grant and Chisholm (1979) map.

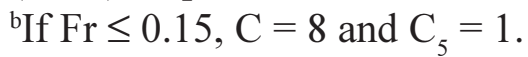

According to Schrage et al. (1988), their expressions for the void fraction and two-phase friction multiplier worked quite well in predicting 
the diabatic total pressure drop data from an experiment carried out by Jensen et al. (1989) using $\mathrm{R}-113$, giving an average absolute deviation between the predictions and the experimental data of $9.8 \%$.

For adiabatic tests, Dowlati et al. (1990; 1992a) calculated the gravitational pressure drop using the bundle average void fraction given by Eq. (4), which was subtracted from the measured pressure drop to obtain the frictional two-phase pressure drop. In this case, the accelerational pressure drop was neglected. For diabatic testes, Dowlati et al. (1996) subtracted also the accelerational pressure drop from the measured total pressure drop to obtain the frictional pressure drop. The accelerational pressure drop component was calculated from the separated flow model given in Collier and Thome (1996). Dowlati et al. (1990; 1992a; 1996) correlated reasonably well the two phase friction multiplier data in terms of a Martinelli parameter with $\mathrm{m}=0.2$. However, strong effects of mass velocity were observed for $G<200$ $\mathrm{kg} / \mathrm{m}^{2} \mathrm{~s}$ and $G<100 \mathrm{~kg} / \mathrm{m}^{2} \mathrm{~s}$ with air water and R113, respectively. The best curve fitting of Eq. (10) to their experimental data was given by distinct $\mathrm{C}$ values according to the tube bundle configuration, whose values are listed in Tab. 3.

Table 3. C values suggested by Dowlati et al. (1990; 1992a; 1996)

\begin{tabular}{cccc}
\hline \hline Fluid & Tube bundle layout & s/D & C \\
\hline \hline air-water & staggered & 1.3 & 20 \\
\hline air-water & in-line & 1.3 & 8 \\
\hline air-water & staggered & 1.75 & 20 \\
\hline air-water & in-line & 1.75 & 50 \\
\hline R-113 & in-line & 1.3 & 20 \\
\hline \hline
\end{tabular}

Comparison of $\mathrm{C}$ factors values from Tabs. 2 and 3, means that increasing the pitch in an inline bundle with a given tube diameter leads to a higher frictional pressure drop. For staggered tube bundles, no s/D effects are noted on the contrary.

Xu et al. (1998b) noted that at a given value of $X_{t t}$ higher than 0.2 , the experimental values decrease with increasing mass velocity. The trend was not clear at a value of $X_{t t}$ up to 0.2 . These findings are similar to those obtained by $\mathrm{Xu}$ et al. (1998a) for horizontal flows. A similar behavior was also noted by Schrage et al. (1988) when $X_{t t}>0.9$. However, according to them, the values increased with increasing mass velocity at a given value of $X_{t t}$ up to 0.9. Xu et al. (1998b) proposed to correlate the two-phase friction multiplier by Eq. (10) with the $\mathrm{C}$ factor being a function of the dimensionless superficial velocity of gas and $\chi /(1-\chi)$ as suggested by Ishihara et al. (1980). By fitting their data, the new $\mathrm{C}$ factor was expressed as follows:

$$
C=A \cdot U{ }_{G}{ }_{G}{ }_{1} \cdot\left(\frac{\chi}{1-\chi}\right)^{b_{2}}
$$

Depending on the direction of flow, distinct values of $A, b_{1}$ and $b_{2}$ were used to fit Eq. (12) to their experimental data. $\mathrm{A}=24.45, \mathrm{~b}_{1}=-0.654$ and $\mathrm{b}_{2}=0.336$ fit the data for upflow and $\mathrm{A}=22.5$, $b_{1}=-0.723$ and $b_{2}=0.340$ fit the data for downflow. For horizontal flow, Xu et al. (1998a) correlated $\phi_{L}^{2}$ by two distinct methods. For annular flow, bubbly flow, intermittent flow and stratifiedannular flow, their data were fit according to Eq. (10). The best curve fit of their data was obtained with $C$ values of 2.4 and 8 for oil-air and water-air, respectively. For the stratified flow pattern, the twophase friction multiplier was correlated in terms of the liquid fraction as follows:

$$
\phi_{L}^{2}=0.507 \cdot(1-\varepsilon)^{-2.811}
$$

with $\varepsilon$ given by Eq. (6). Unfortunately, Xu et al. (1998a; 1998b) also failed to clearly identify how the frictional component of the total pressure drop was obtained.

\section{CONCLUSIONS}

The conclusions drawn from the present literature review involving dynamic aspects of twophase flow across horizontal tube bundles are as follows:

(1) Flow pattern maps based on experimental results for air-water have been proposed. However, no effective effort was applied to identify how the type of flow pattern affects the local void fraction and the two-phase pressure drop. By comparing the proposed maps, it is possible to suggest that a combination of visual observations and an objective flow characterization method seems to be the most reliable procedure to flow pattern evaluation.

(2) Experimental studies on void fractions on the shell side of shell-and-tube heat exchangers 
have focused on obtaining databanks to adjust empirical correlations. In most cases, the proposed correlations depend on fitting coefficients to specific restrictive experimental conditions. Thus, the validity of such correlations at other conditions seems doubtful.

(3) As a general rule, predictive methods for frictional two-phase pressure drop across tube banks are based on the Martinelli model to represent the two-phase friction multiplier. The main objective of the studies concerning this topic is to find either a fixed $\mathrm{C}$ value or a correlation for $\mathrm{C}$ based on their database. However, the use of either can be considered to be restricted to the mass flow range, fluid, tube arrangement, and s/D ratio covered by their experiments.

\section{REFERENCES}

Burnside, B. M., 1999, 2-D Kettle Reboiler Circulation Model, International Journal of Heat and Fluid Flow, Vol. 20, No. 4, pp. 437-445.

Collier, J. G., and Thome, J. R., 1996, Convective Boiling and Condensation, McGrawHill, $3^{\text {rd }}$ edition, New York, USA.

Cornwell, K., 1990, The Influence of Bubbly Flow on Boiling from a Tube in a Bundle, International Journal of Heat and Mass Transfer, Vol. 33, No. 12, pp. 2579-2584.

Diehl, J. E., 1957, Calculate Condenser Pressure Drop, Petroleum Refiner, Vol. 36, pp. 147153.

Dowlati, R., Kawaji, M., and Chan, A. M. C., 1990, Pitch-to-diameter Effect on Two-phase Flow across an In-line Tube Bundle, AIChE Journal, Vol. 36, pp. 765-772.

Dowlati, R., Chan, A. M. C., and Kawaji, M., 1992a, Hydrodynamics of Two-phase Flow across Horizontal In-line and Staggered Rod Bundles, Vol. 114, pp. 450-456.

Dowlati, R., Kawaji, M., Chisholm, D., and Chan, A. M. C., 1992b, Void Fraction Prediction in Two-phase Flow across a Tube Bundle, AIChE Journal, Vol. 38, pp. 619-622.

Dowlati, R., Kawaji, M., and Chan, A. M. C., 1996, Two-phase Crossflow and Boiling Heat Transfer in Horizontal Tube Bundles, Journal of Heat Transfer, Vol. 118, No.1, pp. 124-131.

Feenstra, P. A., Weaver, D. S., and Judd, R. L., 2000, An Improved Void Fraction Model for Two-phase Cross-flow in Horizontal Tube Bundles,
International Journal of Multiphase Flow, Vol. 26, No. 11, pp. 1851-1873.

Feenstra, P. A., Weaver, D. S., and Judd R. L., 2002, Modelling Two-phase Flow-excited Damping and Fluidelastic Instability in Tube Arrays, Journal of Fluids and Structures, Vol. 16, No. 6, pp. 811-840.

Grant, I. D. R., and Chisholm, D., 1979, Two-phase Flow on the Shell-side of a Segmentally Baffled Shell-and-tube Heat Exchanger, Journal of Heat Transfer, Vol. 101, pp. 38-42.

Ishiraha, K., Palen, J. W., and Taborek, J., 1980, Critical Review of Correlations for Predicting Two-phase Flow Pressure Drop across Tube Banks, Heat Transfer Engineering, Vol. 1, pp. 23-32.

Jensen, M. K., Reinke, M. J., and Hsu, J. T., 1989, The Influence of Tube Bundle Geometry on Cross-flow Boiling Heat Transfer and Pressure Drop, Experimental Thermal and Fluid Science, Vol. 2, No. 4, pp. 465-476.

Noghrehkar, G. R., Kawaji, M., and Chan, A. M. C., 1999, Investigation of Two-phase Flow Regimes in Tube Bundles under Cross-flow Condition, International Journal of Multiphase Flow, Vol. 25, No. 5, pp. 857-874.

Rouhani, S. Z., and Axelsson, E., 1970, Calculation of Void Volume Fraction in Subcooled and Quality Boiling Regions, International Journal of Heat and Mass Transfer, Vol. 13, No. 2, pp. 383-393.

Schrage, D. S., Hsu, J. T, and Jensen, M. K., 1988, 2-phase Pressure Drop in Vertical Crossflow across a Horizontal Tube Bundle, AIChE Journal, Vol. 34, No. 1, pp. 107-115.

Ulbrich, R., and Mewes, D., 1994, Vertical, upward Gas-liquid Two-phase Flow across a Tube Bundle, International Journal of Multiphase Flow, Vol. 20, No. 2, pp. 249-272.

Xu, G. P., Tou, K. W., and Tso, C. P., 1998a, Two-phase Void Fraction and Pressure Drop in Horizontal Crossflow across a Tube Bundle, Journal of Fluids Engineering Vol. 120, No. 1, pp. 140-145.

Xu, G. P., Tso, C. P., and Tou, K. W., 1998b, Hydrodynamics of Two-phase Flow in Vertical up and downflow across a Horizontal Tube Bundle, International Journal of Multiphase Flow, Vol. 24, No. 8, pp. 1317-1342.

Zuber, N., and Findlay, J. A., 1965, Average Volumetric Concentration in 2-phase Flow Systems, Journal of Heat Transfer, Vol. 87, No. 4, pp. 453-467. 